\title{
CLINICAL RECORD
}

\section{THREE CASES OF RHINOSPORIDIOSIS}

Case No. I

\author{
By S. K. SEN GUPTA (Calcutta)
}

A male patient, aged 23 years (coming from the district of Bankura, West Bengal, India), was admitted in the E.N.T. Wards under the author on 19.7 .56 , with the following complaints:

I. Gradual difficulty of breathing through the right nasal cavity-duration 3 years.

2. Mucoid discharge through the right nasal cavity-duration 3 years.

3. Bleeding from the right nasal cavity off and on.

\section{History of Illness}

The onset of the complaints was insidious. The patient said that for the last 3 years he felt gradual obstruction in breathing through the right nasal cavity. There was thin mucoid discharge through the right nasal cavity for practically the same period. For the last one year he noticed that a soft fleshy mass was growing in the right nasal cavity, which eventually occluded it. On two occasions during this time of illness he had had bleeding from the nose, but the amount was moderate, and it stopped ordinarily by rest and application of cold on the part. On enquiry no history of allergic manifestations could be detected.

\section{Past History}

He suffered from the same complaints 5 vears prior to the onset of the present symptoms, for which some operations were done inside the nose-the nature of which he could not describe.

\section{Family and Personal History}

Nothing abnormal.

\section{General Survey}

A young man of average height and musculature-looking normal in every respect. Pulse -78 per minute, V.T. moderate, regular. Respiration- $\mathbf{I} 8$ per minute, regular. Temperature $-98 \cdot 2^{\circ} \mathrm{F}$. Blood-pressure- $\mathrm{II} 2 \mathrm{~mm}$. of $\mathrm{Hg}$ systolic-and $76 \mathrm{~mm}$. of $\mathrm{Hg}$ diastolic.

\section{Systemic Examination}

Clinically no abnormality could be detected anywhere. 


\section{Clinical Record}

\section{Special Examination}

Ear, Nose and Throat. The mucous membrane of the left nasal cavity was found healthy. The meati were clear. A soft, granular mass, slightly pinkish in colour was seen protruding from the right nasal aperture. On examination with a probe, the mass was found to be attached to the upper and anterior part of the nasal septum. The mass practically completely obstructed the opening of the nose. Ears, throat, nasopharynx and larynx did not reveal any abnormality.

\section{Blood Examination}

\begin{tabular}{|c|c|c|}
\hline Hæmoglobin & & 80 per cent. \\
\hline Total and Differenti & ial Count & \\
\hline R.B.C. & . & 4.6 million per c.mm. \\
\hline W.B.C. & . & 7,200 cells per c.mm. \\
\hline Polymorphs & . & 70 per cent. \\
\hline Lymphocytes & . & 27 per cent. \\
\hline Monocytes. & . & I per cent. \\
\hline Eosinophils & . & 2 per cent. \\
\hline Coagulation Time & . & $2 \min .20 \mathrm{sec}$ \\
\hline Bleeding Time & . & $2 \mathrm{~min}$ \\
\hline W.R. & . & Negative absolutely \\
\hline Kahn Test .. & . & Negative \\
\hline
\end{tabular}

\section{Treatment}

22.7.56. Under local anæsthesia (I per cent. anethaine solution with a few drops of adrenalin chloride solution) - the soft mass in the right nasal cavity was removed with a nasal snare. The bleeding was controlled by suction and pressure with strips of gauze. The base of the mass was cauterized with electrocautery and the nasal cavity was packed with ribbon gauze soaked in liquid paraffin. The usual post-operative care was taken and sepsis was guarded against by penicillin. The plug was removed on the third day after operation and the nasal cavity was washed with normal saline lotion and subsequently chloretone inhalant (P.D. \& Co.) was sprayed within the nose thrice daily. The convalescent period was uneventful. The patient was discharged on 28.7 .56 (i.e. on the 7 th day after operation) with relief of all his symptoms.

The microscopical section of the mass removed from the nasal cavity is sent herewith-which indicates the features given under the microphotograph. (Figs. I and 2.)

\section{Case No. II}

A male patient, aged I2 years (coming from the district of Khulna-East Pakistan, India) was admitted in the E.N.T. Wards under the author on 24.7 .56 , with the following complaints:

r. Difficulty in breathing through the left nasal cavity due to a soft fleshy mass completely occluding it -2 months. 


\section{S. K. Sen Gupta}

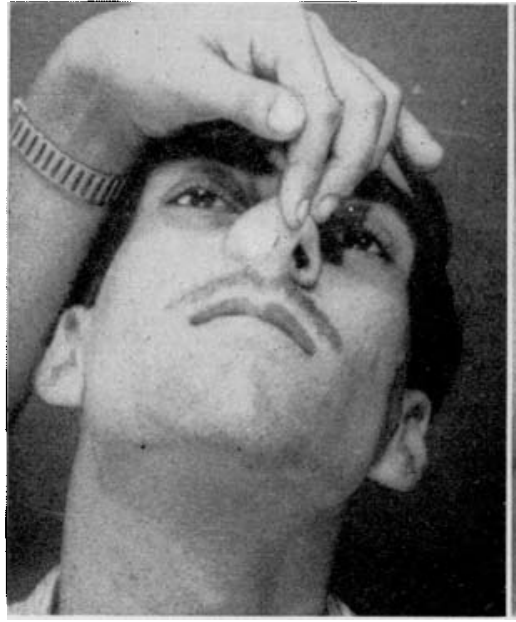

Case I. Before operation.

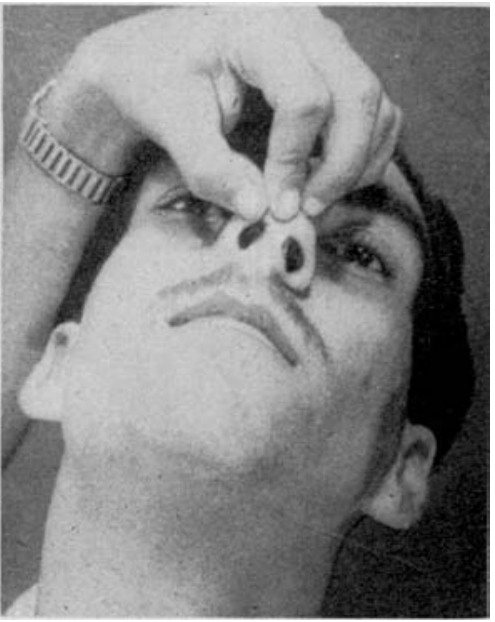

Case I. After operation.

FIG. I.

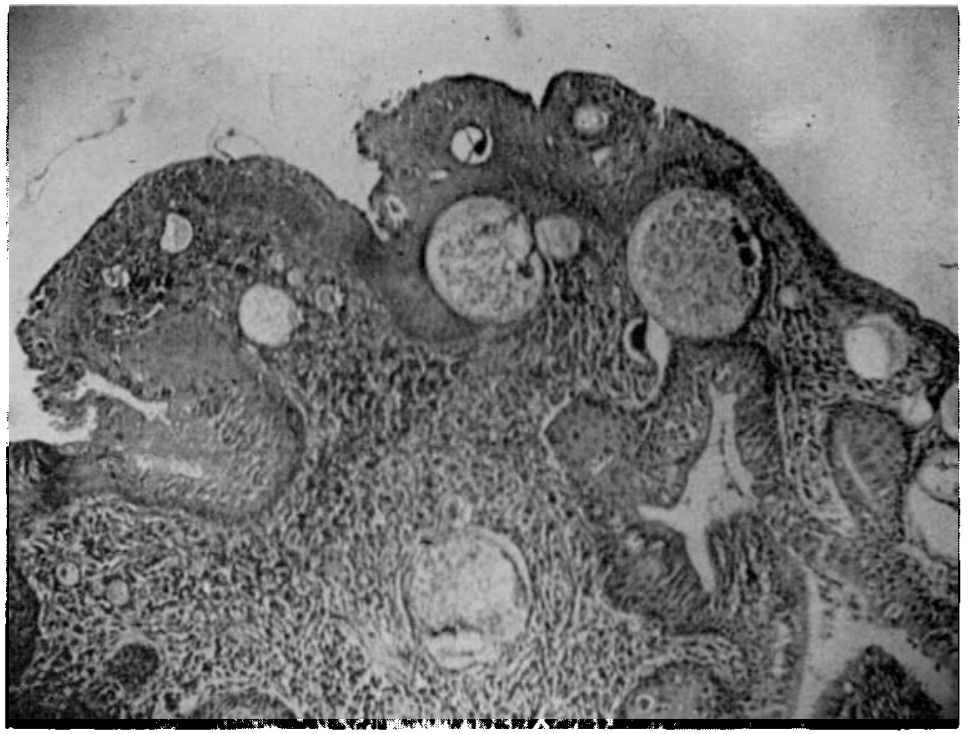

FIG. 2 .

Section I. Shows intact epithelial layers and characters of chronic granuloma with cysts in the subjacent connective tissue. The cysts are of various sizes and containing spores, some mature and some immature. 


\section{Clinical Record}

2. Slight pain over the left side of the nose -2 months.

3. Occasional epistaxis (slight in amount) from the left nasal cavity2 months.

\section{History of Illness}

On enquiry the patient said that for the last couple of months he was having gradual obstruction in the passage of air through his left nasal cavity. A soft fleshy mass was noticed in the left nose 2 months ago by the patient and his relatives. This gradually became bigger and bigger in size till it totally occluded the passage, giving rise to the symptom of difficulty of breathing. He also complained of occasional epistaxis and pain over the left side of the nose.

\section{Past History, Family History, Personal History}

Nothing suggestive detected.

\section{General Survey}

A boy of 12 years, of average height and moderate nutrition--looking healthy and normal in every respect.

Pulse, Respiration, Temperature, Blood-Pressure, Examination of Blood

Within normal limits.

\section{Special Examination}

Ear, nose and throat. The mucosa of the right nasal cavity was found healthy-meati were clear. A soft granular mass, dark red in colour, was seen filling up the left nasal chamber. On examination with a probe, the mass was found to be attached to the lateral wall of the nose. Ears, throat, nasopharynx and larynx did not reveal anything abnormal.

Skiagraphy of the paranasal sinuses - nothing abnormal detected.

\section{Treatment}

Same type of local anæsthesia was employed as in Case No. I. The mass was taken out with a wire-snare. There was considerable amount of bleeding which was controlled by pressure with gauze and suction. The mass was attached to the mucosa of the anterior part of the inferior turbinate. The base was cauterized with electro-cautery and the nasal chamber plugged in the usual way (as in Case No. I). The convalescence was of the same nature as the previous case and the patient was discharged absolutely free from all symptoms on 8.8 .56 (i.e. on the 8 th day after operation).

The microscopical section with notes is sent herewith (Fig. 3).

\section{Case No. III}

A male patient, aged I4 years (coming from the district of Khulna, East Pakistan, India-same as Case No. II) admitted on 8.8.56.

\section{Complaints}

I. Pain in the right nasal cavity-about 2 months.

2. Partial obstruction of the right nasal cavity--about 2 months. 


\section{S. K. Sen Gupta}

\section{Examination of the Nose}

A reddish, fleshy pedunculated mass, about the size of a gram was seen attached to the mucosa at the anterior part of the junction of the floor and the lateral wall of the right nasal cavity. The mass was soft to feel, granular in surface, and mobile.

Pulse, Respiration, Temperature, Blood Examination, Blood-Pressure

Within normal limits.

Skiagraphy of the nasal accessory sinuses-nothing abnormal detected.

\section{General Survey}

A healthy, normal looking boy.

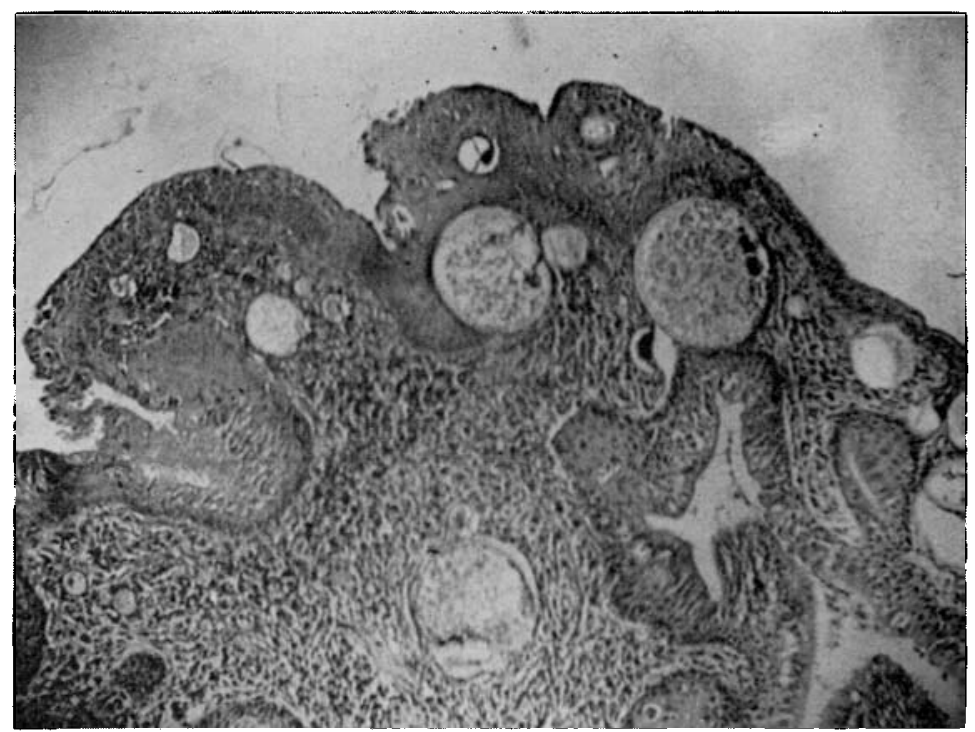

FIG. 3 .

Section II. Shows the cysts have approached to the surface through the epithelial layers and are discharging the mature spores outside.

\section{Treatment}

6.8.56. Same type of anæsthesia was employed as in the other two cases and same nature of operation done. The base of the pedicle was cauterized with fused chromic acid crystals. The convalescence was of the same nature as in the previous cases. The patient was discharged free from all symptoms on 13.8 .56 (i.e. on the 8 th day after the operation).

Unfortunately the microscopical section (the microphotograph) of the mass could not be sent in this case as it did not turn out up to the standard.

\section{Observations}

I. All the three cases came from rural areas.

2. Two of them were cultivators and poor - Case No. I comes of a middleclass educated family. 


\section{Clinical Record}

3. Cases No. II and III came from the same district (Khulna) in East Pakistan, India.

4. Complaints were of same nature in all the cases.

5. The clinical appearance of the mass was similar in all the cases.

6 . The three cases came to the hospital during the same time incidentally.

The following passage from Philip Manson Bahr's "Tropical Diseases Affecting the Ear, Nose and Throat", The Journal of Laryngology and Otology, Vol. LXX, p. I75, is quoted.

"Rhinosporidiosis. This is a disease of the mucous membrane of the nose, caused by a yeast-like organism (some think it is a protozoan) 'Rhinosporidium seeberi' discovered by Seeber in Argentina in $\mathbf{1} 896$. Rhinosporidiosis has been reported from India, Ceylon, Malaya, East Africa, South America, and Southern U.S.A. It takes the form of polypoid masses attached to the turbinates and nasal mucosa and similar growths have been found on the conjunctiva (Garcia, I954) and also on the foot (Allen, 1938). The parasite is spherical or oval, non-motile and occurs in the polypoid growth lying between the connective tissue cells. The earliest stages are almost $6 \mu$ in diameter-and when fully grown the cyst or sporangium may measure 0.25 to $3 \mathrm{~mm}$. The whole cycle has been described in a monograph by Ashworth. Treatment is by removal of the polypi by a wire-snare."

Rhinosporidiosis affecting the naso-lacrymal duct has been reported by Dr. H. Hazra, M.B.(Cal.), F.R.C.S.(Edin.), D.L.O.(Lond.), and Dr. M. C. Misra, M.B.B.S.(Patna), D.O.M.S.(Lond.), in the Indian Journal of Otolaryngo$\log y$ in June, 1956, Vol. VIII, No. 2, p. $8 \mathrm{I}$.

My thanks to my House-Surgeons, Dr. Ashish Mazumdar and Nripen Roy, and to the Professor of Pathology, Dr. N. Mondal, and to Dr. B. Chakraverti, Professor of Dermatology and Microphotographic Expert for helping me to publish these cases. 